\title{
Endovascular Neurosurgery: A History of Electricity, Balloons, Wires and Glue
}

\section{Fernando Gonzalez, MD, Mitchell Maltenfort, PhD \\ Department of Neurological Surgery, Thomas Jefferson University Hospital, Philadelphia, PA}

\section{Endovascular:}

procedures and techniques that use a vessel (artery or vein) as the route to establish diagnosis or treat diseases
Physicians may have first known what an aneurysm was as far back as the $14^{\text {th }}$ Century BC in Egypt ${ }^{1}$, but by the early $19^{\text {th }}$ century they were still trying to find satisfactory options for treating large or surgically inaccessible aneurysms. ${ }^{4,5}$ One of the techniques being considered was inserting a needle to provoke formation of a clot that would close off the aneurysm. The proof that this technique could work was discovered by C. H. Moore in 1864, during an autopsy of a gunshot victim. The bullet, lodged in the ascending aorta, was embedded in fibrin. Based on this, Moore speculated that a wire could be introduced into the body through a small wound, but then passed up to the aneurysm where it would coil and attract fibrin to block the aneurysm. Moore used 26 yards of coil to treat a thoracic aorta aneurysm; the patient died of sepsis, but the aneurysm had decreased in pulsation and size before that, and autopsy confirmed that the coils had promoted fibrin clotting as predicted. Later efforts trying a variety of materials, ranging from iron wire to gold-plated watch springs, also had poor outcomes. Attempts using electrical current to provoke clots during this period did not produce a consistent benefit either. ${ }^{5,6}$

A large part of the problem was that no one could see where they were going. At that time, aneurysms could only be seen by opening the patient. The X-ray was not discovered until 1895 , and X-rays alone would not show the arteries. In 1896, Haschek and Lindenthal in 1896 could make the arteries in a cadaver's hand visible under X-ray, but only through injecting substances that would be poison to a living being. ${ }^{7}$ It was not until 1927 that Egas Moniz was able to find a contrast agent that was tolerable to living humans, founding the technique of cerebral angiography or arteriography. In 1937, Walter Dandy performed the first clipping of an aneurysm. ${ }^{8}$ In this particular case, the aneurysm was readily seen during surgery, so there was no need for cerebral angiography, although Dandy did note in his Discussion that "In general, the indications for operation at the Circle of Willis... are none too clear... without a knowledge of the side of the circle of Willis upon which the aneurysm is located there would be no justification in exploring either side in search of the lesion...Arteriography may here become an important means of locating one of these aneurysms..." The first aneurysm clipped that took advantage of perioperative angiography was performed by Normal Dott in 1933. ${ }^{9}$ By 1951 , carotid angiography was referred to as "routine" and "safe and relatively simple" and vertebral angiographies had a failure rate of thirty percent although they were done by direct carotid puncture. ${ }^{10}$ Sean Mullan used a stereotactic frame to localize and apply electricity directly to aneurysms, causing thrombosis. ${ }^{11}$

The first step towards modern endovascular surgery was taken by Luessenhop and Velasquez who used an inflatable catheter (i.e., a balloon) to occlude aneurysms and arteriovenous malformations. ${ }^{12}$ In 1965, JF Alksne $e^{13,14}$ used a magnetic field to guide iron spheres into aneurysms. Because iron spheres turned out to have a risk of fragmentation, the technique was modified to use acrylic spheres in which iron powder was suspended. In a series of 22 patients treated this way ${ }^{15}$, there was no morbidity or rebleeding and the aneurysm was completely occluded in 17 patients. Angiography was used both pre-operatively to locate the aneurysm and post-operatively to confirm the success of the procedure. Fedor Serbienko, a Russian neurosurgeon, pioneered the use of detachable balloons for the treatment of carotid cavernous fistulas. Serbienko designed and made the balloons himself after much trial and error with silicone and latex ${ }^{16-18}$
A problem with the balloon catheter is that it could not conform to the geometry of the aneurysm. The modern era of endovascular neurosurgery may have begun with the detatchable platinum coils developed by Guido Guglielmi, a neurosurgeon and expert in electricity. ${ }^{19,20}$ Guglielmi patented a system where a platinum coil attached to a stainless steel wire could be detached using electrolysis when a current was applied to the wire.

Fifteen patients with aneurysms in size ranging fromless than $12 \mathrm{~mm}$ to greater than $25 \mathrm{~mm}$ were treated in the first series, with consistent success (70\% to $100 \%$ occlusion) and no fatalities or persistent neurological deficits. The Guglielmi detachable coils provided conforming blockage of the aneurysms plus clot formation through both the presence of wire and the electricity passed through the coils to detach them. The system has had multiple itierations, including adding bioactive agents to the coils to promote clotting ${ }^{21}$, but still holds the same principle.

It was noted that this technique was not very successful in wide neck aneurysms, where the coils could herniate into the parent vessel or where adequate aneurysm filling might not be obtained. At first, inflatable balloons were used to support the coils during the procedure. In the later 1980's and 1990's the large experience with use of cardiac stents gave rise to the concept of stent-assisted coiling. The stent, a hollow tube, acts as a scaffold to support the coils.

\section{Stent:}

Charles T. Stent (1807-1885) was a dentist who developed a compound for taking dental impressions in 1856. His compound was later used by a plastic surgeon as a facial filler. The story goes that the word shifted over time to describe a device that holds vessels open, which is a familiar and valuable device to vascular surgeons and their patients. ${ }^{2,3}$

One technique being considered in the future is flow diversion, where modified stents are used to exclude the aneurysm from the 

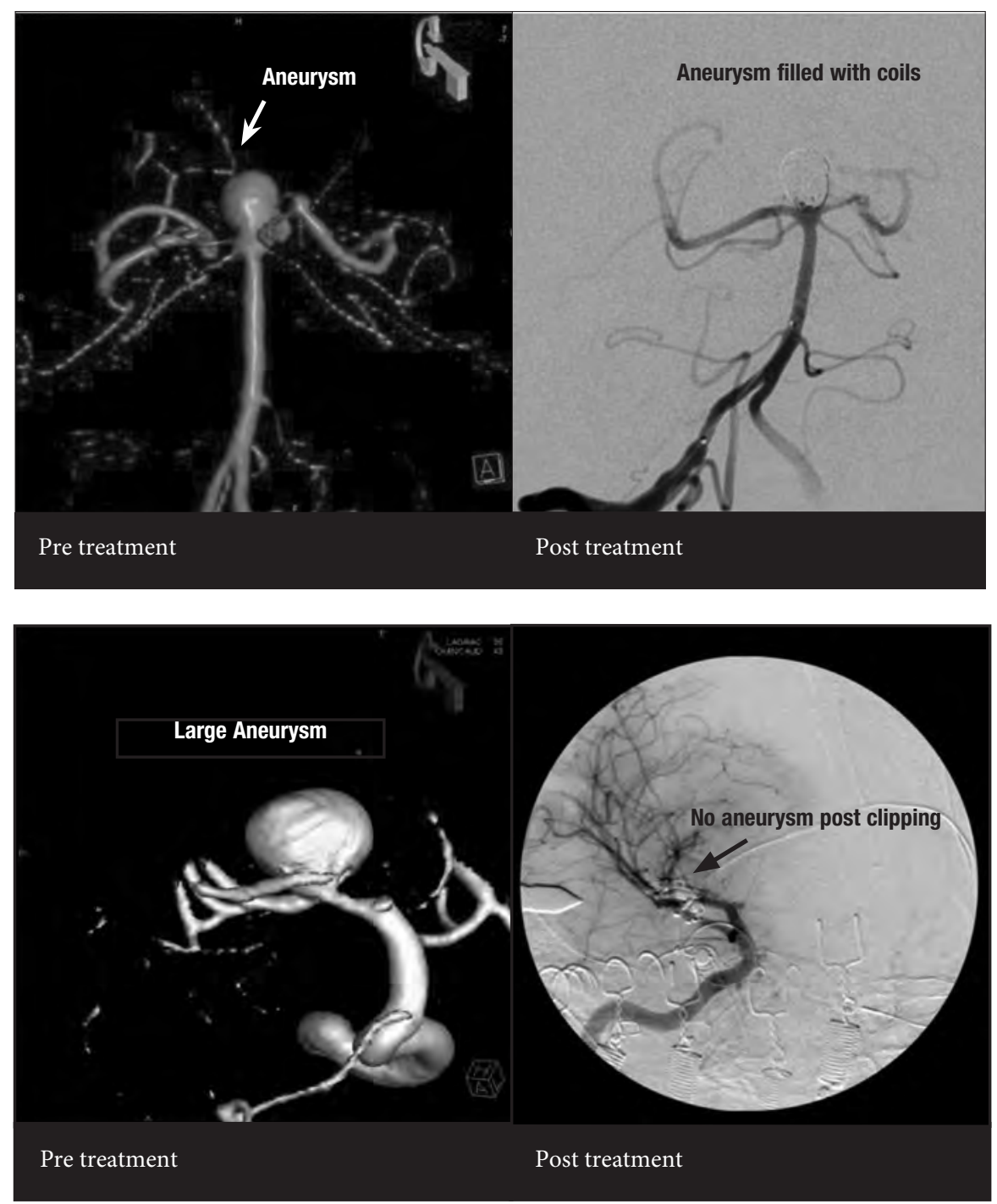

circulation without explicit ligation or packing of the aneurysm..$^{22,23}$ Anecdotal experience with stents shows that the aneurysm may shrink or disappear with the stent by itself. Studies using computer simulation ${ }^{24,25}$ show that the stent design can be modified to divert the flow from the aneurysm without using coils. Liquid embolic agents are also being used to block aneurysms and anteriovenous malformations ${ }^{26}$, such as the Onyx agent now being used here at TJU. Stay tuned.

\section{References}

1. Stehbens WE: History of aneurysms. Med Hist 2:274-280, 1958.

2. Meier B: Stenting, quite a legacy of Charles, Charles, and Arthur. Cathet Cardiovasc Diagn 45:233-234, 1998.

3. Ring ME: How a dentist's name became a synonym for a life-saving device: the story of Dr. Charles Stent. J Hist Dent 49:77-80, 2001.

4. Prestigiacomo CJ: Historical perspectives: the microsurgical and endovascular treatment of aneurysms. Neurosurgery 59:S39-47; discussion S33-13, 2006

5. Siddique K, Alvernia J, Fraser K, Lanzino G: Treatment of aneurysms with wires and electricity: a historical overview. J Neurosurg 99:1102-1107, 2003.
6. Kanaan Y, Kaneshiro D, Fraser K, Wang D, Lanzino G: Evolution of endovascular therapy for aneurysm treatment. Historical overview. Neurosurg Focus 18:E2, 2005.

7. Sovak M: From iodide to iotrolan: history and argument Eur Radiol 5 Suppl 2:S3-7, 1995.

8. Dandy WE: Intracranial Aneurysm of the Internal Carotid Artery: Cured by Operation. Ann Surg 107:654-659, 1938.

9. Todd NV, Howie JE, Miller JD: Norman Dott's contribution to aneurysm surgery. J Neurol Neurosurg Psychiatry 53:455-458, 1990.

10. Sutton D, Hoare RD: Percutaneous vertebral arteriography. Br J Radiol 24:589-597, 1951

11. Mullan S: Stereotactic thrombosis of intracranial aneurysms. Confin Neurol 31:94, 1969

12. Luessenhop AJ, Velasquez AC: Observations on the Tolerance of the Intracranial Arteries to Catheterization. J Neurosurg 21:85-91, 1964.

13. Alksne JF, Fingerhut AG, Rand RW: Magnetically controlled focal intravascular thrombosis in dogs. J Neurosurg 25:516$525,1966$.

14. Alksne JF, Fingerhut AG, Rand RW: Magnetic probe for the stereotactic thrombosis of intracranial aneurysms. J Neurol Neurosurg Psychiatry 30:159-162, 1967.

15. Smith RW, Alksne JF: Stereotaxic thrombosis of inaccessible intracranial aneurysms. J Neurosurg 47:833-839, 1977.

16. Serbinenko FA: Balloon catheterization and occlusion of major cerebral vessels. J Neurosurg 41:125-145, 1974

17. Teitelbaum GP, Larsen DW, Zelman V, Lysachev AG, Likhterman LB: A tribute to Dr. Fedor A. Serbinenko, founder of endovascular neurosurgery. Neurosurgery $46: 462$ 469; discussion 469-470, 2000

18. White RJ: A tribute to Dr. Fedor A. Serbinenko, founder of endovascular neurosurgery. Neurosurgery 47:795, 2000

19. Guglielmi G, Vinuela F, Dion J, Duckwiler G: Electrothrombosis of saccular aneurysms via endovascular approach. Part 2: Preliminary clinical experience. J Neurosurg 75:8-14, 1991.

20. Guglielmi G, Vinuela F, Sepetka I, Macellari V: Electrothrombosis of saccular aneurysms via endovascular approach. Part 1: Electrochemical basis, technique, and experimental results. J Neurosurg 75:1-7, 1991.

21. Veznedaroglu E, Koebbe CJ, Siddiqui A, Rosenwasser RH: Initial experience with bioactive cerecyte detachable coils: impact on reducing recurrence rates. Neurosurgery 62:799805; discussion 805-796, 2008

22. Crowley RW, Evans AJ, Kassell NF, Jensen ME, Dumont AS: Endovascular treatment of a fusiform basilar artery aneurysm using multiple "in-stent stents". Technical note. J Neurosurg Pediatr 3:496-500, 2009.

23. Sadasivan C, Cesar L, Seong J, Rakian A, Hao Q, Tio FO, Wakhloo AK, Lieber BB: An original flow diversion device for the treatment of intracranial aneurysms: evaluation in the rabbit elastase-induced model. Stroke 40:952-958, 2009.

24. Kim M, Levy EI, Meng H, Hopkins LN: Quantification of hemodynamic changes induced by virtual placement of multiple stents across a wide-necked basilar trunk aneurysm. Neurosurgery 61:1305-1312; discussion 1312-1303, 2007.

25. Kim M, Taulbee DB, Tremmel M, Meng H: Comparison of two stents in modifying cerebral aneurysm hemodynamics. Ann Biomed Eng 36:726-741, 2008.

26. Prestigiacomo CJ: Surgical endovascular neuroradiology in the 21st century: what lies ahead? Neurosurgery 59:S48-55 discussion S43-13, 2006. 